\title{
Fluctuating asymmetry of the needles of Pinus brutia var. pityusa (STEVEN) SILBA, 1985, growing in industrial and recreational areas in Tuapse
}

\author{
$G$ Kozlov $^{1}, M$ Pushkarev $^{1, *}, I$ Belyaeva $^{1}, A$ Maksimova $^{1}, S$ Shvidkoy ${ }^{1}$, and $D$ Belyaev $^{1}$ \\ ${ }^{1}$ Saint-Petersburg State Institute of Technology, 190013, 26 Moskovsky prospect, St. Petersburg, \\ Russia
}

\begin{abstract}
The paper provides information on the index of fluctuating asymmetry of the Pitsunda pine in industrial and recreational areas in the city of Tuapse (the Russian Black Sea coast of the Caucasus). It is shown that pollution is localized in the port area, and in the city center, the fluctuating asymmetry index is comparable to that for resort areas at a considerable distance from the Tuapse port. The necessity of taking into account the climate when using the coefficient of fluctuating asymmetry of the needles of the Mediterranean (Pitsunda) pine in assessing the degree of ecological well-being of various areas is shown.
\end{abstract}

\section{Introduction}

The Russian Black Sea coast of the Caucasus is a unique region that combines resort, transport and agricultural importance. On its territory, there are nature reserves and large trade ports, resorts and powerful industrial enterprises, agricultural land and sports facilities. The population density, especially in the summer, reaches the level characteristic of a metropolis. All this puts a huge burden on the natural environment. Monitoring of the state of the environment is necessary, and bioindication is one of its tools. Previously, we assessed the state of the environment in resort and industrial areas on the Black Sea coast of the Caucasus (Gelendzhik, Anapa, Novorossiysk, Divnomorskoe) [1]. The aim of this work is to study in detail the fluctuating asymmetry of the Pitsunda pine Pinus brutia var. pityusa (Steven) Silba, 1985, in the industrial and recreational areas of the city of Tuapse.

\section{Materials and methods}

The herbarium was collected ut in the following locations: (2) cargo port; (3) Nebug village (resort area); (4) Beach area in the vicinity of Kiselev rock (natural monument); (5) Tuapse city center. The coordinates were determined by a GPS navigator. The length of the needles was measured with a ruler with a division value of $0.5 \mathrm{~mm}$. The fluctuating asymmetry was

\footnotetext{
*Corresponding author: malexpush@bk.ru
} 
calculated according to the formula (1) [2] (the ratio of the difference in the lengths of the right and left needles of the paired needles to their average value):

$$
A s_{f l}=2 * \frac{L_{1}-L_{2}}{L_{1}+L_{2}}
$$

where: $L_{1}$ - left needle length;

$L_{2}$ - length of the right needle of the paired needles.

\section{Results and discussion}

The herbarium was collected in the amount of 400-450 pairs of needles. The sufficiency of this sample size is justified by a separate auxiliary observation (Fig. 1). The average value of the fluctuating asymmetry changes significantly depending on the sample size due to outliers. However, already at $\mathrm{n}=250-300$, the average value stabilizes. The measurements were taken for the needles of Pinus brutia TEN., 1811 (location: Turkey, resort 36 40'58 "N, 30 34'11" E coordinates), a variety of which is Pinus brutia var. pityusa (Steven) Silba, 1985.

$$
\text { Location } 1 \text { (Turkey) }
$$

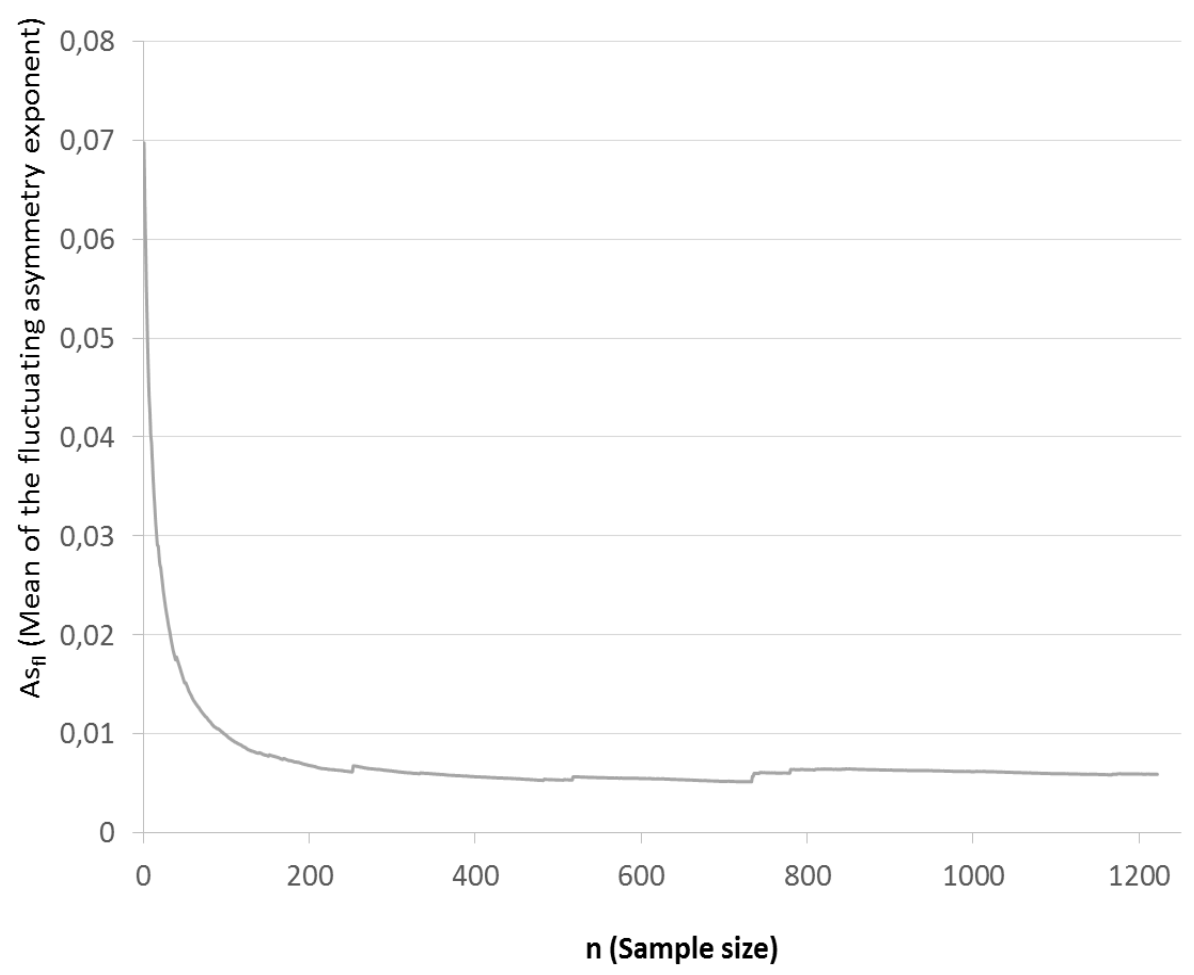

Fig. 1. Dependence of the fluctuating asymmetry of the needles of the Turkish pine Pinus brutia on the sample size for a recreational area. 
The results are shown in Fig. 2 and in Table 1. The average value of fluctuating asymmetry stabilizes at sample sizes of 200-250 and differ for resort and industrial areas. The industrial location is characterized by high air pollution (a terminal for transshipment of mineral fertilizers and a coal terminal are located nearby). Recreational areas (Table 1, locations 3-5) have an index of fluctuating asymmetry that actually coincide with each other, while their value is almost two times lower than that for an industrial area (table 1, location 2). The difference in the indices of fluctuating asymmetry is caused by the effect of a combination of unfavorable environmental factors, for example, for Scots pine (Pinus sylvestris), it was shown [3] that the value of the fluctuating asymmetry index is proportional to pollution by toxic metals, and it is very sensitive, first of all, to the content of copper and zinc [4]. There are data on the influence of radioactive contamination on the value of this value [5]. The actual state of the indicator plant is the result of the cumulative effect of various stress factors acting over a long time [4]. Thus, the index of fluctuating asymmetry should be correlated not with the level of specific pollution, but with the total average annual level of pollution, expressed in the total number of MPC units. It should be noted that the use of the fluctuating asymmetry index to compare the degree of pollution of locations with significant climatic differences (in our case, the coast of the Black and Mediterranean Seas) can give false positive or false negative results. The coefficient of fluctuating asymmetry in the resort area of the Turkish coast of the Mediterranean Sea (location 1) is close to that for the port of Tuapse, but the conclusion about the pollution of the resort area, comparable to the area of the port, where coal and mineral fertilizers are transshipped, will clearly be wrong. 


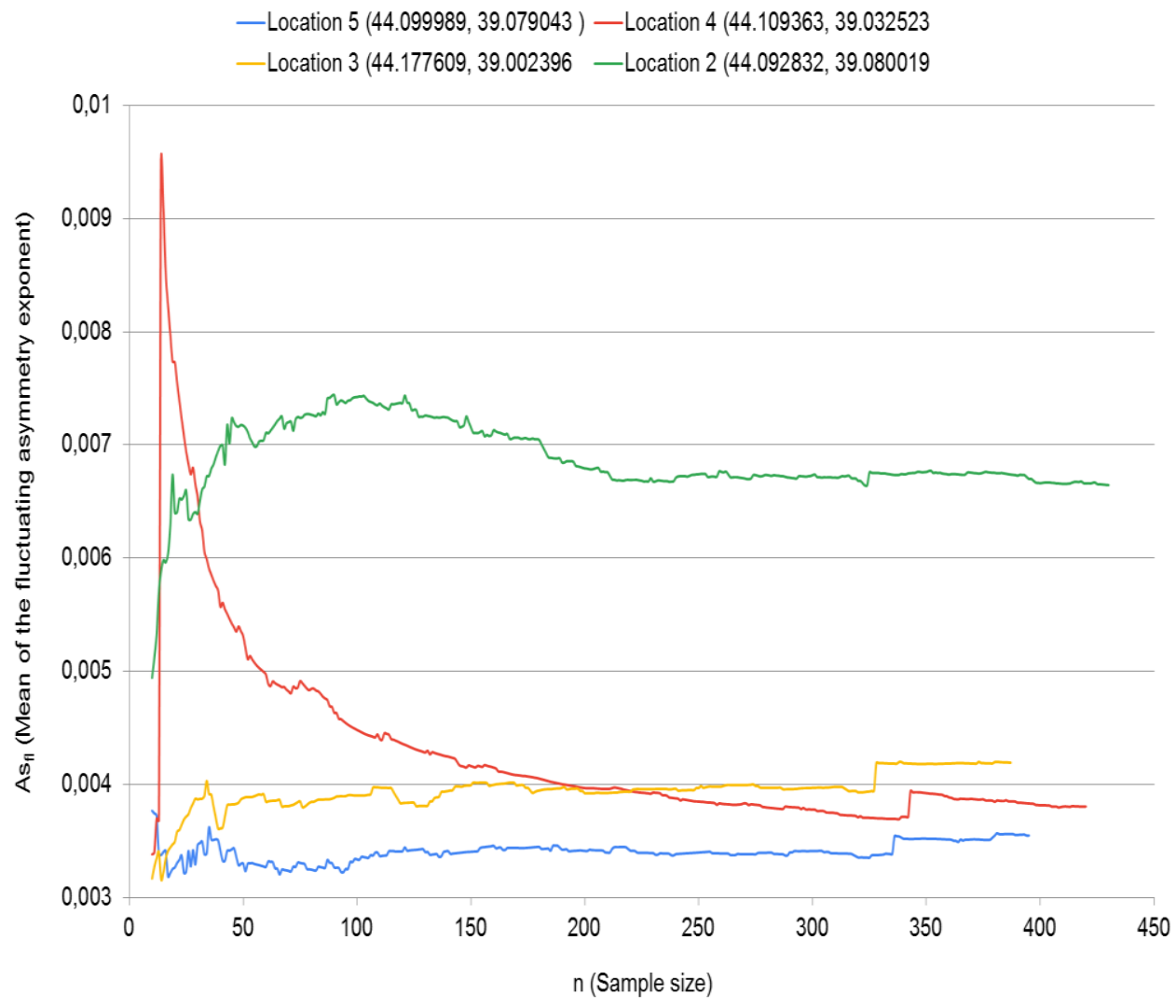

Fig. 2. Dependence of the fluctuating asymmetry of the needles of the Turkish pine Pinus brutia var. pityusa on the sample size for various recreational and industrial areas in Tuapse.

Table 1. The results of determining the fluctuating asymmetry of the needles of Pinus brutia var. pityusa (Steven) Silba, 1985 in various locations in Tuapse.

\begin{tabular}{|c|c|c|c|c|c|c|c|}
\hline 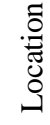 & Coordinates & $\mathrm{n}$ & $\min$ & $\max$ & Mean & $\mathrm{S}$ & $\begin{array}{c}\mathrm{M} \pm \mathrm{m} \\
(\mathrm{p}=0.05)\end{array}$ \\
\hline 1 & $36.682777,30.569722$ & 1230 & 0 & 0.5867 & 0.005899 & 0.024384 & $(5.90 \pm 0.04) \mathrm{e}-3$ \\
\hline 2 & $44.092832,39.080019$ & 430 & 0 & 0.0436 & 0.00665 & 0.003527 & $(6.65 \pm 0.33) \mathrm{e}-3$ \\
\hline 3 & $44.177609,39.002396$ & 387 & 0 & 0.0843 & 0.00419 & 0.00437 & $(4.19 \pm 0.44) \mathrm{e}-3$ \\
\hline 4 & $44.109363,39.032523$ & 420 & 0 & 0.0855 & 0.00382 & 0.00574 & $(3.82 \pm 0.55) \mathrm{e}-3$ \\
\hline 5 & $44.099989,39.079043$ & 395 & 0 & 0.0559 & 0.00354 & 0.003325 & $(3.54 \pm 0.33) \mathrm{e}-3$ \\
\hline
\end{tabular}




\section{Conclusions}

Air pollution in the port of Tuapse is significant, but localized in the area of emission sources, and in the center (recreational zone), the fluctuating asymmetry index is comparable to locations that are very remote from pollution sources.

When using the index of fluctuating asymmetry of the needles of Pitsunda pine, it is necessary to use reference points in the same climatic zone as the control points, otherwise the influence of climatic conditions can lead to false positive or false negative results.

This work was supported by the state mission of the Ministry of Science and Higher Education of the Russian Federation (785.00.X6019).

\section{References}

1. Kozlov G, Pushkarev M, Kozlov A, and Perepelitsa E 2020 Bioindication for the Search of Microorganisms-Destructors Advances in Intelligent Systems and Computing 676-684 doi:10.1007/978-3-030-57453-6_64

2. Palmer A R, Strobeck C 2003 Fluctuating asymmetry analyses revisited Developmental instability: causes and consequences (New York: Oxford Univ. Press.) 279-319

3. Kozlov M V and Niemelä P 1999 Difference in Needle Length - A New and Objective Indicator of Pollution Impact on ScotsPine (PinusSylvestris) Water Air Soil Poll. 116 365-370

4. Chudzinska E, Pawlaczyk E M, Celinski K, Diatta J 2014 Response of Scots pine (Pinussylvestris L.) to stress induced by different types of pollutants - testing the fluctuating asymmetry Water and Environment Journal 28 533-539

5. Møller, Anders Pape 1998 Developmental Instability of Plants and Radiation from Chernobyl Oikos 81(3 ) 444-448 JSTOR www.jstor.org/stable/3546765.Accessed 10 Mar. 2020. 